\title{
The customer satisfaction of maintenance as a factor in improving the performance of maintenance
}

\author{
Teonas Bartza , Virgílio Mathes ${ }^{\mathrm{b}}$, Julio Cezar Mairesse Siluk ${ }^{\mathrm{a}}$ \\ oFederal University of Santa Maria \\ University Centre Univates \\ e-mails: efficacy.consultoria@gmail.com; virgilio.ems@brasilata.com.br; jsiluk@ufsm.br
}

\begin{abstract}
This paper presents a case study fulfilled at the maintenance sector of a metallurgical company. The research problem addressed was the satisfactions level of customers of the maintenance. The objective was to quantify the performance of preventive and corrective maintenance, mechanical and electrical, in relation to customer satisfaction. To achieve this aim, we conducted an applied research, quantitative, developed by a case study. With the knowledge of some theoretical models of performance measurement, we adopted the Key Performance Indicators - KPI - as the most suitable method for measuring proposal. With this, it developed questionnaires to assess the satisfaction of the performance of maintenance. After the data collection, spreadsheets were created to quantify the answers to the questionnaires. The results of this study present the responses to the seven requirements that assess the satisfaction of preventive maintenance and six requirements that assess customer satisfaction of corrective maintenance services. It is concluded that the measurement of maintenance performance, by measuring customer satisfaction becomes important criterion for planning and ascertainment of industry guidelines for maintenance of the company.
\end{abstract}

Keywords: maintenance, customer satisfaction, indicators, evaluation of the performance, competitiveness.

\section{Introduction}

The evolution of manufacturing models, both mass production and the introduction of lean manufacturing, is increasingly important to the maintenance sector of companies. Carnero (2006) suggests that the policy of maintenance management has evolved from the short-term goals for long-term strategic goals. Kans and Ingwald (2008) argue that maintenance has been significant and essential for companies to increase their competitiveness, and describe it as an integrated and coordinated as part of the production process. Khalil, Saad and Gindy (2009) point to the growing interest of companies in developing maintenance strategies based on prevention. This is used to reduce unplanned downtime of production equipment, helping to reduce operating costs.

Thus, the unplanned maintenance must not exist or have a very low rate of occurrence. The unplanned maintenance is classified as the only intervention performed on the equipment when it is not operating conditions (MOAYED; SHELL, 2009). Even with awareness of the need to work more to prevent and eliminate unplanned maintenance, Peres and Lima (2008) point out that maintenance still needs strategic direction and policies for the function that is responsible for managing the operation of enterprises to help achieve planned results.
Maintenance activities have an impact interface and in virtually all other operations of a company. Thus, management should focus on all areas of involvement that influences others to maintain productive and nonproductive sectors of a company. One way to manage maintenance activities is the evaluation of performance indicators $d$ maintenance. Bartz and Siluk (2011), based on Muchiri et al. (2011) suggest some indicators for the management of maintenance, such as: number of preventive maintenance and unplanned maintenance, preventive maintenance time, mean time between failures - MTBF and mean time to repair-MTTR. In addition to these indicators, there is the Overall Equipment Effectiveness - OEE.

This paper aims to present metrics for performance evaluation of the satisfaction of the activities of the maintenance sector of a metallurgical company. After the creation of the assessment requirements, we applied the model developed to understand the evolution and improvement of service for maintenance.

The paper is organized with the following sections from this. Section 2 presents theoretical performance evaluation of maintenance and its importance for competitiveness. Section 3 presents the methodology used to conduct the research. Since section 4 shows the proposed requirements for the performance indicator related to customer satisfaction in 
the maintenance sector and two approaches to perform the determination of the satisfaction index. The last section shows the conclusions drawn about the application of the proposed models.

\section{Theoretical reference}

This section presents the theoretical concepts discussed during the development of research and application of the model developed for performance evaluation of the maintenance sector of the company studied. This on the subject of maintenance management, performance indicators and performance of maintenance.

\subsection{Maintenance management}

The need for maintenance is as old as the production equipment. However, evolution is always note in historical times as the industrial revolution, the First World War, the phase change provided by the Second World War and, more recently, the introduction of lean production models. Moraes (2004, p. 25) shows this development, divided into three generations as shown in Figure 1.

The maintenance seen as strategic for the vision begins to interfere with the systemic organizational results. It seeks more than just perform the corrective maintenance, search quality and productivity. These elements, combined with maintenance management, which form an efficient production system, as growing competition and constant development of technology mean that companies seek changes in the management of maintenance and greater participation of all persons involved in the production process (OTANI; MACHADO, 2008; KHAN; DARRAB, 2010; TAKAHASHI; OSADA, 2010).
The main types of maintenance are: corrective, that does the intervention after the fall; a preventive program that maintenance activities based on time or the condition of the equipment; the predictive, which optimizes the exchange of parts or reform components and extend the maintenance interval; and Total Productive Maintenance, seeking the involvement of all people in maintenance activities (VERRI, 2007).

\subsection{Performance indicators}

The use of performance measurement in organizations advances had more pronounced with the measurement of financial results. In industry there are still improvements to be made in the manufacturing, logistics, quality, commercial and other (OLIVEIRA et al., 2010). Despite the need for improvements in enforcement, many performance measurement models are available for application in organizations.

In the industrial area and major departments in an organization, performance indicators are a way for us to define, assess and there is a schedule of improvements in performance of organizational activities. Thus, the model of KPI measures the performance and involves all levels of an organization in achieving strategic goals. The KPI serve to reduce the complexity of the performance of the organization to a small number of indicators, for the purpose of manageability. So are individual KPIs, i.e. each company defines which indicators are most relevant to their guidelines are met (LATORRE; ROBERTS; RILEY, 2010).

The performance indicators relate to internal management of all processes, such as quality, cost, delivery, productivity and availability of production equipment. Thus, the

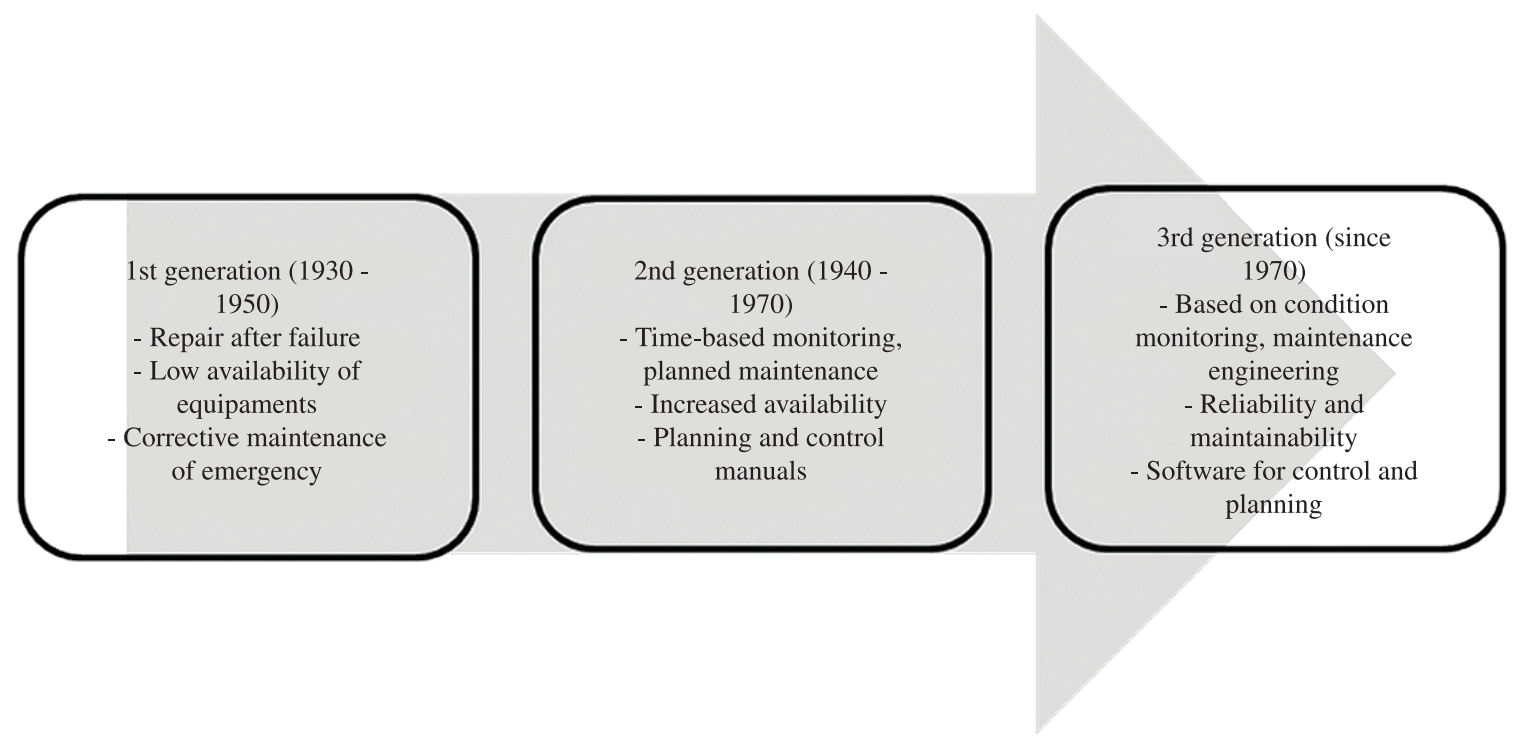

Figure 1. Evolution of maintenance (MORAES, 2004). 
performance indicators are used to learn and improve; demonstrate compliance processes to stakeholders, and, control and monitor those involved in the processes (SILVA; CABRITA; MATIAS, 2008).

A KPI provides the most important performance information, enabling monitoring and management guidelines, showing that the organization is achieving or not achieving the goals. Thus, the implementation of the KPI's start with the identification of the objectives of the organization to enable it to fulfill its mission and bring value to everyone involved with the organization. Once defined, is to monitor and measure them (BARTZ; SILUK; BARTH, 2011).

\subsection{Performance of maintenance}

The performance of the maintenance indicators can be quantified by, divided into two groups: the main indicators and maintenance of the maintenance indicators. Measuring the performance of maintenance is a strategic factor for companies that only achieve the desired improvements from process control. As in all areas of business, performance measurement aims at continuous improvement. In the maintenance this objective cannot be different (AHRÉN; PARIDA, 2009),

The maintenance performance indicators are used when one wants to evaluate the influence of process maintenance on manufacturing performance. In the evaluation of manufacturing performance are related to productivity, availability, quality and capacity utilization. The identification of what will be the maintenance indicators to adopt will be based on the organization's strategy, aligning the goals and targets contained in its planning (PARIDA, 2007).

To Parida and Kumar (2006), measuring the performance of maintenance has some basic goals, such as measuring the value created for the maintenance, justify the company's investment in maintenance, planning investment in improvements, make improvements related to health, safety and the work-environment. In addition to these basic objectives is to measure the performance of maintenance that will be raised the need to change the design or maintenance strategy used by organizations.

The main process indicators assess whether maintenance tasks are being performed properly and if the results are obtained later. To verify these objectives are evaluated to identify the work, planning of maintenance activities, programming and execution of tasks. Already, the indicators deal primarily the result of the availability of equipment for production, reliability and operating conditions of the same (MUCHIRI et al., 2011).

The maintenance performance indicators commonly used by businesses are: availability, cost, Mean Time Between Failures - MTBF, Mean Time To Repair - MTTR,
Backlog, frequency of failure, customer satisfaction, rework and other (ASSOCIAÇÃO..., 2009).

\section{Method}

The methodology adopted for the process of conducting scientific studies can be classified on different aspects, i.e. the research is evaluated as: the use, nature, objectives and techniques. Furthermore, the methodology discusses how the data will be collected and shape of sampling collection thereof. After collecting data, also need to analyze them and interpret them (TRIVIÑOS, 1987; SILVA; MENEZES, 2001; CERVO; BERVIAN, 2002; GIL, 2010).

The studied company has 16 production lines with production capacity of $1,800 \mathrm{t}$ per month. It has 337 employees and a building area of $17,000 \mathrm{~m}^{2}$. The development of the research took place in the maintenance sector, which meets all lines of production and printing industry. Currently the sector accounts for the services of electrical and mechanical maintenance and has 20 professionals trained to perform preventive maintenance, corrective and predictive.

This study is considered an applied research, since it makes use of published knowledge available and seeking a solution to a specific problem, i.e., measuring the performance of maintenance performed and customer satisfaction in relation to these services. The nature of the research is classified as quantitative, since the data are collected through questionnaires completed by customers of the service sector and tabulated to quantify the performance index of each and every maintenance requirement. In relation to the objectives, this research is classified as descriptive, since its purpose is to describe the relationship between customer satisfaction and performance improvement in the maintenance sector assessed.

As for the research technique was developed a case study, which began with the preparation of a literature review on some models of performance measurement of maintenance. The case study examines deeply and thoroughly a few objects of study, allowing the researcher to know them in detail. Five features of the case study are: the survey questions, its propositions, its unit of analysis, logic linking data to propositions and criteria for interpreting the findings (YIN, 2005).

Regarding the involvement of the researcher, this study is an action research, it makes a close relationship between an action and resolution of a problem with which the researcher is involved (THIOLLENT, 2008). The data collection instrument used was questionnaire, which has different models for preventive and corrective maintenance, where the informant mark the type of service performed and mechanical or electrical service scores with grades 1-10.

To conduct this case study created a working group led by researchers and with the participation of mechanics, 
maintenance technicians and maintenance planner for the requirements definition of the satisfaction questionnaire. Afterwards, the questionnaire was designed and conducted the pre-test to assess the acceptance and understanding of the requirements addressed. To complete the questionnaire system was adopted in scores between 1 and 10 .

After approval of the questionnaire were created spreadsheets for data entry and generation of control charts in comparison with the targets set for each and every maintenance requirement. For comparison with the targets were used, Equation 1 and 2.

Equation 1 shows the average performance of each maintenance performed, where " $n$ " represents the number of requirements scored, seven to six for preventive maintenance and corrective maintenance. The result shows the percentage of satisfaction with the service running

Maintenance mean $=\frac{\sum_{\mathrm{i}=1}^{\mathrm{n}} \text { Requirements scored }}{\text { Number of requirements scored }} \times 10$ (1)

The Equation 2 shows the average monthly performance of each requirement assessed, depending on the number of maintenance in the month. The result represents the percentage of satisfaction of the requirement assessed before any maintenance undertaken during the period.

Requirement mean $=\frac{\sum_{\mathrm{i}=1}^{\mathrm{n}} \text { Maintenances scored }}{\text { Number of maintenaces performed }} \times 10(2$

The evaluation of maintenance performance was divided into preventive and corrective, electrical and mechanical services. This division was made on the basis of ease of actions taken based on the level of satisfaction generated by planning maintenance activities according to the metric of performance indicators proposed by Muchiri et al. (2011).

\section{Results}

Data collection satisfaction of maintenance services evaluated in this study began in June 2011 and lasted until the month of February 2012. During the nine months of collection, questionnaires were distributed to each end of the activities planned or preventive maintenance work orders according to corrective maintenance. For corrective maintenance requirements were evaluated: cleaning, service time of the request, service quality, efficiency after maintenance, communication between maintenance and production sectors, and time to resumption of operation of the equipment. The questionnaires for assessing the preventive maintenance: cleaning, delivery, service quality, efficiency after maintenance, improvement and innovation, communication between sectors, and allotted time for the final adjustment of the equipment.

\subsection{Preventive maintenance}

The target set for each requirement was $85 \%$ satisfaction. Each month, in which the target is not met, corrective actions are taken of the requirement, to evaluate what the causes and measures to be taken to improve the maintenance process. Table 1 shows the results of the satisfaction evaluation of preventive maintenance services for the period studied, with the requirement cleaning.

It is observed from the data presented, which in July 2011 all indices were below the target of $85 \%$. Once this has occurred, improvement actions have been taken, mainly in electrical maintenance, where the rate was only $60 \%$, well below the limit. After this, every month after the overall cleanliness of the requirement met the goal.

Table 2 shows the monitoring of delivery of equipment within the specified preventive maintenance. This is because preventive maintenance is performed with the machine stopped production, and combines a number of hours available for the execution of the service sector of production planning, so that demand is not affected production.

Also there was a requirement that does not meet the target only in July 2011. Another highlight is the performance of electrical maintenance in the months of August and October 2011, where it reached $100 \%$ on-time delivery schedule. The results regarding the quality of preventive maintenance services are shown in Table 3.

Table 1. Satisfaction of preventive maintenance - cleaning.

\begin{tabular}{|c|c|c|c|c|c|c|c|c|c|}
\hline & $\mathbf{J}(\boldsymbol{\%})$ & $\mathbf{J}(\boldsymbol{\%})$ & $\mathbf{A}(\boldsymbol{\%})$ & $\mathbf{S}(\boldsymbol{\%})$ & $\mathbf{O}(\boldsymbol{\%})$ & $\mathbf{N}(\boldsymbol{\%})$ & $\mathbf{D}(\boldsymbol{\%})$ & $\mathbf{J}(\boldsymbol{\%})$ & $\mathbf{F}(\boldsymbol{\%})$ \\
\hline Mechanical & 93 & 80 & 87 & 89 & 86 & 88 & 86 & 86 & 93 \\
\hline Electrical & 80 & 60 & 95 & 90 & 100 & 90 & 90 & 85 & 80 \\
\hline General & 93 & 79 & 87 & 89 & 87 & 88 & 86 & 86 & 93 \\
\hline
\end{tabular}

Table 2. Satisfaction of preventive maintenance - deadline.

\begin{tabular}{|c|c|c|c|c|c|c|c|c|c|}
\hline & $\mathbf{J}(\boldsymbol{\%})$ & $\mathbf{J}(\boldsymbol{\%})$ & $\mathbf{A}(\boldsymbol{\%})$ & $\mathbf{S}(\boldsymbol{\%})$ & $\mathbf{O}(\boldsymbol{\%})$ & $\mathbf{N}(\boldsymbol{\%})$ & $\mathbf{D}(\boldsymbol{\%})$ & $\mathbf{J}(\boldsymbol{\%})$ & $\mathbf{F}(\boldsymbol{\%})$ \\
\hline Mechanical & 92 & 85 & 89 & 87 & 88 & 91 & 91 & 88 & 92 \\
\hline Electrical & 90 & 80 & 100 & 90 & 100 & 90 & 90 & 85 & 90 \\
\hline General & 92 & 84 & 90 & 87 & 89 & 91 & 91 & 87 & 92 \\
\hline
\end{tabular}


The quality of preventive maintenance has remained stable between August and December 2011. Earlier, in July 2011 that the index below the target, reaching 78\%, while maintaining electrical won only $60 \%$ satisfaction. Even so, note that the electrical maintenance has little influence on the overall result, since the number of mechanical maintenance is higher than the number of electrical maintenance.

Still, it is observed that there was no attendance target of $85 \%$ in January 2012, also because of the electrical maintenance was below the stipulated $68 \%$, a fact that had already occurred in November 2010, when the index was $70 \%$. As there was recurrence, corrective actions were taken, which resulted in an increase in satisfaction to $90 \%$ in February 2012.

Data on production efficiency after the execution of maintenance will s shown in Table 4. The efficiency is measured by taking the number of parts made per shift in function of the productive capacity of the period.

Also, it is observed that in the months - July and November 2011 and January 2012 - the electrical maintenance was below the target of $85 \%$. On average the period analyzed, the efficiency after maintenance is $86.2 \%$. Even though the above objective it is important to improve this ratio, since the yield depends on the reliability of the equipment, it is important that maintenance of a back into its normal operating both productivity and quality.

Table 5 shows the considerations made about the innovations and improvements proposed by the maintenance sector, adopting the maintenance engineering, which seeks to improve the equipment, materials and other points, can improve the quality and life of the machine.

Although not easy to implement improvements and innovations in the company's equipment since the equipment has high-tech, it can be observed since November 2011 the goal is being met. That depends on which maintenance is scheduled and what equipment.

Table 6 shows data communication between the sectors of mechanical maintenance and production. This requirement is considered very important, because the mechanics of mind with daily live production equipment and have the information of the production operators.

It is observed that this requirement has always fulfilled the goal, although in July 2011, the electrical maintenance to be with $80 \%$ approval. It is considered that these ratios are well evaluated because since the beginning of activities for performance measurement of maintenance, the mechanics of production and maintenance were involved, both in developing the questionnaire and the application of the pre-test it.

While performing preventive maintenance, maintenance mechanics perform general activities. Thus, the adjustment device for each operation is performed in conjunction with the mechanical output. It was determined that each programmed maintenance, $20 \%$ of the time would be allocated for the adjustment of the final product. Table 7 shows the evaluation of this requirement.

Table 3. Satisfaction of preventive maintenance - quality of service.

\begin{tabular}{|c|c|c|c|c|c|c|c|c|c|}
\hline & $\mathbf{J}(\boldsymbol{\%})$ & $\mathbf{J}(\boldsymbol{\%})$ & $\mathbf{A}(\boldsymbol{\%})$ & $\mathbf{S}(\boldsymbol{\%})$ & $\mathbf{O}(\boldsymbol{\%})$ & $\mathbf{N}(\boldsymbol{\%})$ & $\mathbf{D}(\boldsymbol{\%})$ & $\mathbf{J}(\boldsymbol{\%})$ & $\mathbf{F}(\boldsymbol{\%})$ \\
\hline Mechanical & 91 & 79 & 86 & 87 & 86 & 87 & 88 & 87 & 91 \\
\hline Electrical & 90 & 60 & 100 & 90 & 95 & 70 & 98 & 68 & 90 \\
\hline General & 91 & 78 & 87 & 87 & 87 & 86 & 89 & 84 & 91 \\
\hline
\end{tabular}

Table 4. Satisfaction of preventive maintenance - efficiency after maintenance.

\begin{tabular}{|c|c|c|c|c|c|c|c|c|c|}
\hline & $\mathbf{J}(\boldsymbol{\%})$ & $\mathbf{J}(\boldsymbol{\%})$ & $\mathbf{A}(\boldsymbol{\%})$ & $\mathbf{S}(\boldsymbol{\%})$ & $\mathbf{O}(\boldsymbol{\%})$ & $\mathbf{N}(\boldsymbol{\%})$ & $\mathbf{D}(\boldsymbol{\%})$ & $\mathbf{J}(\boldsymbol{\%})$ & $\mathbf{F}(\boldsymbol{\%})$ \\
\hline Mechanical & 91 & 74 & 89 & 90 & 84 & 87 & 89 & 86 & 91 \\
\hline Electrical & 80 & 60 & 100 & - & 95 & 70 & 98 & 63 & 80 \\
\hline General & 91 & 73 & 89 & 90 & 85 & 86 & 89 & 82 & 91 \\
\hline
\end{tabular}

Table 5. Satisfaction of preventive maintenance - innovation and improvement.

\begin{tabular}{|c|c|c|c|c|c|c|c|c|c|}
\hline & $\mathbf{J}(\boldsymbol{\%})$ & $\mathbf{J}(\boldsymbol{\%})$ & $\mathbf{A}(\boldsymbol{\%})$ & $\mathbf{S}(\boldsymbol{\%})$ & $\mathbf{O}(\boldsymbol{\%})$ & $\mathbf{N}(\boldsymbol{\%})$ & $\mathbf{D}(\boldsymbol{\%})$ & $\mathbf{J}(\boldsymbol{\%})$ & $\mathbf{F}(\boldsymbol{\%})$ \\
\hline Mechanical & 91 & 79 & 81 & 89 & 79 & 90 & 84 & 89 & 91 \\
\hline Electrical & 90 & - & - & - & 90 & 90 & 95 & 87 & 90 \\
\hline General & 91 & 79 & 81 & 89 & 81 & 90 & 85 & 88 & 91 \\
\hline
\end{tabular}

Table 6. Satisfaction of preventive maintenance - communications between maintenance and production sectors.

\begin{tabular}{|c|c|c|c|c|c|c|c|c|c|}
\hline & $\mathbf{J}(\boldsymbol{\%})$ & $\mathbf{J}(\boldsymbol{\%})$ & $\mathbf{A}(\boldsymbol{\%})$ & $\mathbf{S}(\boldsymbol{\%})$ & $\mathbf{O}(\boldsymbol{\%})$ & $\mathbf{N}(\boldsymbol{\%})$ & $\mathbf{D}(\boldsymbol{\%})$ & $\mathbf{J}(\boldsymbol{\%})$ & $\mathbf{F}(\boldsymbol{\%})$ \\
\hline Mechanical & 89 & 85 & 88 & 90 & 87 & 88 & 88 & 88 & 90 \\
\hline Electrical & 80 & 80 & 90 & 90 & 100 & 90 & 85 & 87 & 80 \\
\hline General & 89 & 85 & 88 & 90 & 88 & 88 & 88 & 88 & 89 \\
\hline
\end{tabular}


We observe the data in Table 7; only in July 2011 the target was not met. The response to this goal is important for the proper functioning of the equipment after maintenance requirements and other influences, such as equipment efficiency. Thus, the higher this ratio, the more will tend to increase the satisfaction and efficiency after maintenance.

Some criteria used in measuring the performance of preventive maintenance were also adopted in the evaluation of customer satisfaction of corrective maintenance. It is observed that in some months there is no evaluation. This was because there was no corrective maintenance period. Table 8 shows the customer satisfaction in relation to cleaning of the equipment when performing corrective maintenance.

Despite being an emergency service, satisfaction of this requirement is above the target, except the month of August 2011. Still, compared to the satisfaction of the same requirement of preventive maintenance, it is observed that the average for the period studied is higher, reaching $91.4 \%$ versus $87.5 \%$ of preventive maintenance.

Since corrective maintenance occur when equipment needs to operate, fast service the call is important so that the same return as fast to produce. Thus we evaluated the time to treatment of these calls, and this data shown in Table 9.

It is observed that in all months, the goal was met, especially the months of June 2011 and February 2012, in which the index of satisfaction reached $98 \%$. This demonstrates the involvement of maintenance personnel to meet the emergency demands of the production sector, a fact crucial to maintaining productivity, quality and competitiveness of their market.

As in preventive maintenance services, service quality was also assessed in corrective services, and these data shown in Table 10.

Despite being an activity correction, which requires the speed, quality cannot be forgotten. Thus, it is considered that the satisfaction with the service quality of corrective maintenance is very good, especially also the months of June 2011 and January and February 2012, where the rates exceeded $96 \%$.

The productive efficiency of the equipment after completion of corrective maintenance is shown in Table 11.

It is observed that in most months there was no corrective maintenance of electrical nature, a fact considered excellent. Although the goal of meeting in July 2011 to January 2012, where the index reached $99 \%$ in the month of February the rate was $80 \%$ below target. Also communication between sectors is important for the rapid restoration of equipment operation. Therefore, this requirement is also evaluated for corrective maintenance, and the data shown in Table 12 .

The contents of communication between the sectors have a high satisfaction rate, which demonstrates the connectedness and participation of both sectors in solving the problems. The latter requirement evaluated for corrective maintenance, shown in Table 13, it is time to restore the machine to normal operation.

Table 7. Satisfaction of preventive maintenance - time allotted for final adjustment.

\begin{tabular}{|c|c|c|c|c|c|c|c|c|c|}
\hline & $\mathbf{J}(\boldsymbol{\%})$ & $\mathbf{J}(\boldsymbol{\%})$ & $\mathbf{A}(\boldsymbol{\%})$ & $\mathbf{S}(\boldsymbol{\%})$ & $\mathbf{O}(\boldsymbol{\%})$ & $\mathbf{N}(\boldsymbol{\%})$ & $\mathbf{D}(\boldsymbol{\%})$ & $\mathbf{J}(\boldsymbol{\%})$ & $\mathbf{F}(\boldsymbol{\%})$ \\
\hline Mechanical & 88 & 81 & 85 & 87 & 87 & 90 & 89 & 89 & 90 \\
\hline Electrical & 60 & 80 & 100 & 90 & 95 & 90 & 90 & 90 & 60 \\
\hline General & 88 & 81 & 86 & 87 & 88 & 90 & 89 & 89 & 88 \\
\hline
\end{tabular}

Table 8. Satisfaction of corrective maintenance - cleaning.

\begin{tabular}{|c|c|c|c|c|c|c|c|c|c|}
\hline & $\mathbf{J}(\boldsymbol{\%})$ & $\mathbf{J}(\boldsymbol{\%})$ & $\mathbf{A}(\boldsymbol{\%})$ & $\mathbf{S}(\boldsymbol{\%})$ & $\mathbf{O}(\boldsymbol{\%})$ & $\mathbf{N}(\boldsymbol{\%})$ & $\mathbf{D}(\boldsymbol{\%})$ & $\mathbf{J}(\boldsymbol{\%})$ & $\mathbf{F}(\boldsymbol{\%})$ \\
\hline Mechanical & 98 & 86 & 80 & 88 & 93 & 93 & 91 & 94 & 98 \\
\hline Electrical & - & 80 & 95 & - & - & 90 & - & 95 & - \\
\hline General & 98 & 85 & 83 & 88 & 93 & 93 & 91 & 94 & 98 \\
\hline
\end{tabular}

Table 9. Satisfaction of corrective maintenance - time to call.

\begin{tabular}{|c|c|c|c|c|c|c|c|c|c|}
\hline & $\mathbf{J}(\boldsymbol{\%})$ & $\mathbf{J}(\boldsymbol{\%})$ & $\mathbf{A}(\boldsymbol{\%})$ & $\mathbf{S}(\boldsymbol{\%})$ & $\mathbf{O}(\boldsymbol{\%})$ & $\mathbf{N}(\boldsymbol{\%})$ & $\mathbf{D}(\boldsymbol{\%})$ & $\mathbf{J}(\boldsymbol{\%})$ & $\mathbf{F}(\boldsymbol{\%})$ \\
\hline Mechanical & 98 & 89 & 88 & 89 & 92 & 93 & 94 & 93 & 98 \\
\hline Electrical & - & 70 & 100 & - & - & 80 & - & 100 & - \\
\hline General & 98 & 86 & 90 & 89 & 92 & 92 & 94 & 95 & 98 \\
\hline
\end{tabular}

Table 10. Satisfaction of corrective maintenance - quality of service.

\begin{tabular}{|c|c|c|c|c|c|c|c|c|c|}
\hline & $\mathbf{J}(\boldsymbol{\%})$ & $\mathbf{J}(\boldsymbol{\%})$ & $\mathbf{A}(\boldsymbol{\%})$ & $\mathbf{S}(\boldsymbol{\%})$ & $\mathbf{O}(\boldsymbol{\%})$ & $\mathbf{N}(\boldsymbol{\%})$ & $\mathbf{D}(\boldsymbol{\%})$ & $\mathbf{J}(\boldsymbol{\%})$ & $\mathbf{F}(\boldsymbol{\%})$ \\
\hline Mechanical & 98 & 90 & 83 & 87 & 84 & 92 & 90 & 95 & 98 \\
\hline Electrical & - & 80 & 95 & - & - & 70 & - & 100 & - \\
\hline General & 98 & 88 & 85 & 87 & 84 & 90 & 90 & 96 & 98 \\
\hline
\end{tabular}


Table 11. Satisfaction of corrective maintenance - efficiency after maintenance.

\begin{tabular}{|c|c|c|c|c|c|c|c|c|c|}
\hline & $\mathbf{J}(\boldsymbol{\%})$ & $\mathbf{J}(\boldsymbol{\%})$ & $\mathbf{A}(\boldsymbol{\%})$ & $\mathbf{S}(\boldsymbol{\%})$ & $\mathbf{O}(\boldsymbol{\%})$ & $\mathbf{N}(\boldsymbol{\%})$ & $\mathbf{D}(\boldsymbol{\%})$ & $\mathbf{J}(\boldsymbol{\%})$ & $\mathbf{F}(\boldsymbol{\%})$ \\
\hline Mechanical & 80 & 91 & 84 & 90 & 94 & 90 & 87 & 98 & 80 \\
\hline Electrical & - & 80 & 100 & - & - & 70 & - & 100 & - \\
\hline General & 80 & 89 & 88 & 90 & 94 & 89 & 87 & 99 & 80 \\
\hline
\end{tabular}

Table 12. Satisfaction of corrective maintenance - communications between maintenance and production sectors.

\begin{tabular}{|c|c|c|c|c|c|c|c|c|c|}
\hline & $\mathbf{J}(\boldsymbol{\%})$ & $\mathbf{J}(\boldsymbol{\%})$ & $\mathbf{A}(\boldsymbol{\%})$ & $\mathbf{S}(\boldsymbol{\%})$ & $\mathbf{O}(\boldsymbol{\%})$ & $\mathbf{N}(\boldsymbol{\%})$ & $\mathbf{D}(\boldsymbol{\%})$ & $\mathbf{J}(\boldsymbol{\%})$ & $\mathbf{F}(\boldsymbol{\%})$ \\
\hline Mechanical & 98 & 88 & 88 & 90 & 94 & 95 & 89 & 98 & 98 \\
\hline Electrical & - & 80 & 98 & - & - & 80 & - & 100 & - \\
\hline General & 98 & 87 & 90 & 90 & 94 & 94 & 89 & 99 & 98 \\
\hline
\end{tabular}

Table 13. Satisfaction of corrective maintenance - time to restore the equipment.

\begin{tabular}{|c|c|c|c|c|c|c|c|c|c|}
\hline & $\mathbf{J}(\boldsymbol{\%})$ & $\mathbf{J}(\boldsymbol{\%})$ & $\mathbf{A}(\boldsymbol{\%})$ & $\mathbf{S}(\boldsymbol{\%})$ & $\mathbf{O}(\boldsymbol{\%})$ & $\mathbf{N}(\boldsymbol{\%})$ & $\mathbf{D}(\boldsymbol{\%})$ & $\mathbf{J}(\boldsymbol{\%})$ & $\mathbf{F}(\boldsymbol{\%})$ \\
\hline Mechanical & 95 & 89 & 86 & 88 & 93 & 96 & 91 & 95 & 95 \\
\hline Electrical & - & 70 & 100 & - & - & - & - & 95 & - \\
\hline General & 95 & 85 & 88 & 88 & 93 & 96 & 91 & 95 & 95 \\
\hline
\end{tabular}

There was in this condition, an improved since the start of measurement of performance. From July 2011, where the rate was $85 \%$, there is a positive trend of growth in this indicator, rising to $88 \%$ in August and September 2011, to $93 \%$ in October 2011, to $96 \%$ in November 2011 and stabilize at $95 \%$ in January and February 2012.

\section{Conclusions}

In the case study conducted, it is clear that although satisfaction of maintenance services to meet the targets set during most months studied, it is observed that improvement is still possible, making the company more productive and increases their competitiveness. The adoption of performance indicators for the maintenance sector facilitated the collection of data and assist in the planning of improvement actions and identifying the need for investment, both financial and training of those involved in maintenance. Therefore, the KPIs used in this article addresses first the initial needs of the maintenance sector, for further planning activities more complex and can be measured with the introduction of new performance indicators for maintenance. Importantly, the analysis of the indicator of customer satisfaction in the service industry introduced the assessment of the causes of problems and planning actions to eliminate these, striving for continuous improvement and development goals.

Whereas the maintenance as a strategic sector for the company to achieve its objectives, both in production and financial indicators, measuring performance of this sector has brought a change in behavior involved. The main change can be observed in the requirements for reporting. This demonstrates the involvement that the maintenance staff has with the productive activities of the company. It also shows the importance of this sector to the productive results is achieved.

Thus, we conclude that the performance indicator of customer satisfaction of maintenance, the company created to become essential if the area manager to analyze the maintenance process. This will facilitate their decisionmaking and continuous improvement actions, making the sector more efficient and more satisfying the needs and expectations of its customers.

\section{References}

AHRÉN, T.; PARIDA, A. Maintenance performance indicators (MPIs) for benchmarking the railway infrastructure: a case study. Benchmarking: An International Journal, v. 16, n. 2, p. 247-258, 2009.

ASSOCIAÇÃO BRASILEIRA DE MANUTENÇÃO ABRAMAN. A situação da manutenção no Brasil: documento nacional 2009. Rio de Janeiro: ABRAMAN, 2009.

BARTZ, T.; SILUK, J. C. M. Evaluation of maintenance performance in a Metalworking Company: a case study and proposal of new indicators. Product: Management \& Development, v. 9, n. 1, p. 77-85, 2011.

BARTZ, T.; SILUK, J. C. M.; BARTH, L. E. Importância da mensuração de desempenho industrial na indústria: um estudo de caso. Revista Brasileira de Estratégia, v. 4, n. 1, p. 91-104, 2011.

CARNERO, M. C. An evaluation system of the setting up of predictive maintenance programmes. Reliability Engineering and System Safety, v. 91, n. 8, p. 945-963, 2006. http://dx.doi.org/10.1016/j.ress.2005.09.003

CERVO, A. L.; BERVIAN, P. A. Metodologia científica. 5. ed. São Paulo: Prentice Hall, 2002. 
GIL, A. C. Métodos e técnicas de pesquisa social. 6. ed. 3. reimpr. São Paulo: Atlas, 2010.

KANS, M.; INGWALD, A. Common database for cost-effective improvement of maintenance performance. International Journal Production Economics, v. 113, n. 2, p. 734-747, 2008. http://dx.doi.org/10.1016/j.ijpe.2007.10.008

KHALIL, J.; SAAD, S. M.; GINDY, N. An integrated cost optimization maintenance model for industrial equipment. Journal of Quality in Maintenance Engineering, v. 15, n. 1, p. 106-118, 2009. http://dx.doi. org/10.1108/13552510910943912

KHAN, M. R. R.; DARRAB, I. A. Development of analytical relation between maintenance, quality and productivity. Journal of Quality in Maintenance Engineering, v. 16, n. 4, p. 341-353, 2010. http://dx.doi. org/10.1108/13552511011084508

LATORRE, V.; ROBERTS, M.; RILEY, M. J. Development of a Systems Dynamics Framework for KPIs to Assist Project Managers' Decision Making Processes. Revista de la Construcción, v. 9, n. 1, p. 39-49, 2010. http://dx.doi. org/10.4067/S0718-915X2010000100005

MOAYED, F.; SHELL, R. L. Comparison and evaluation of maintenance operations in lean versus non-lean production systems. Journal of Quality in Maintenance Engineering, v. 15, n. 3, p. 285-296, 2009. http://dx.doi. org/10.1108/13552510910983224

MORAES, P. H. A. Manutenção produtiva total: estudo de caso em uma empresa automobilística. 2004. Dissertação (Mestrado em Gestão e Desenvolvimento Regional)Universidade de Taubaté, Taubaté, 2004.

MUCHIRI, P. et al. Development of maintenance function, performance measurement frame work and indicators. International Journal of Production Economics, v. 131, n. 1, p. 295-302, 2011. http://dx.doi.org/10.1016/j. ijpe.2010.04.039

OLIVEIRA, K. F. et al. Processo de medição de desempenho em micro e pequenas empresas de um Arranjo Produtivo Local. INGEPRO, v. 02, n. 11, p. 48-59, 2010.
OTANI, M.; MACHADO, W. V. A proposta de desenvolvimento de gestão da manutenção industrial na busca da excelência ou classe mundial. Revista Gestão Industrial, v. 4, n. 2, p. 01-16, 2008. http://dx.doi.org/10.3895/S180804482008000200001

PARIDA, A. Study and analysis of maintenance performance indicators (MPIs) for LKAB: a case study. Journal of Quality in Maintenance Engineering, v. 13, n. 4, p. 325-337, 2007.

PARIDA, A.; KUMAR, U. Maintenance performance measurement (MPM): issues and challenges. Journal of Quality in Maintenance Engineering, v. 12, n. 3, p. 239-251, 2006.

PERES, C. R. C.; LIMA, G. B. A. Proposta de modelo para controle de custos de manutenção com enfoque na aplicação de indicadores balanceados. Gestão \& Produção, v. 15, n. 1, p. 149-158, 2008. http://dx.doi.org/10.1590/S0104530X2008000100013

SILVA, C. M. I.; CABRITA, C. M. P.; MATIAS, J. C. O. Proactive reliability maintenance: a case study concerning maintenance service costs. Journal of Quality in Maintenance Engineering, v. 14, n. 4, p. 343-355, 2008.

SILVA, E. L.; MENEZES, E. M. Metodologia da pesquisa e elaboração de dissertação. 3. ed. rev. atual. Florianópolis: Laboratório de Ensino a Distância da UFSC, 2001.

TAKAHASHI, Y.; OSADA, T. TPM/MPT: manutenção produtiva total. 4. ed. São Paulo: Instituto IMAM, 2010.

THIOLLENT, M. Metodologia da pesquisa-ação. 16. ed. São Paulo: Cortez, 2008.

TRIVIÑOS, A. N. S. Introdução à pesquisa em ciências sociais: a pesquisa qualitativa em educação. São Paulo: Atlas, 1987.

VERRI, L. A. Gerenciamento pela qualidade total na manutenção industrial: aplicação prática. Rio de Janeiro: Qualitymark, 2007.

YIN, R. K. Estudo de caso: planejamento e métodos. 3. ed. Porto Alegre: Bookman, 2005. 